\title{
Analysis of electro-mechanical interaction in aircraft generator systems
}

DOI:

10.1109/TIA.2016.2585088

\section{Document Version}

Accepted author manuscript

Link to publication record in Manchester Research Explorer

\section{Citation for published version (APA):}

Feehally, T., Erazo Damian, I., \& Apsley, J. (2016). Analysis of electro-mechanical interaction in aircraft generator systems. IEEE Transactions on Industry Applications, 52(5), 4327-4336. https://doi.org/10.1109/TIA.2016.2585088

\section{Published in:}

IEEE Transactions on Industry Applications

\section{Citing this paper}

Please note that where the full-text provided on Manchester Research Explorer is the Author Accepted Manuscript or Proof version this may differ from the final Published version. If citing, it is advised that you check and use the publisher's definitive version.

\section{General rights}

Copyright and moral rights for the publications made accessible in the Research Explorer are retained by the authors and/or other copyright owners and it is a condition of accessing publications that users recognise and abide by the legal requirements associated with these rights.

\section{Takedown policy}

If you believe that this document breaches copyright please refer to the University of Manchester's Takedown Procedures [http://man.ac.uk/04Y6Bo] or contact uml.scholarlycommunications@manchester.ac.uk providing relevant details, so we can investigate your claim.

\section{OPEN ACCESS}




\title{
Analysis of electro-mechanical interaction in aircraft generator systems
}

\author{
Tom Feehally, Iñaki Erazo Damian, Judith Apsley \\ School of Electrical and Electronic Engineering, \\ The University of Manchester, Manchester, UK \\ tom.feehally@manchester.ac.uk
}

\begin{abstract}
The supply of electrical power is usually achieved by a generator, driven from a prime mover, by some form of mechanical drivetrain. Such an electro-mechanical system will have natural resonant modes in both the electrical and mechanical subsystems. The electrical generator provides a coupling between the subsystems, transferring not only useful power but also disturbances between electrical and mechanical domains: these disturbances may excite resonances resulting in cross-domain (electro-mechanical) interaction. This can lead to lifetime reduction in the mechanical components and instability in the electrical network, resulting in poor reliability for the wider system, and potentially catastrophic component failure. Electro-mechanical interaction is particularly critical in power generation systems onboard aircraft, because the generator is driven by a gas turbine via an inherently low-stiffness drive train. It is then critical to identify electro-mechanical interaction at the design stage so that these issues can be avoided. However, predicting the occurrence of interaction, through simulation, is challenging, requiring multi-domain models, operating with different time scales. This paper analyses an aircraft auxiliary power offtake to produce a reduced-order mechanical drivetrain model, allowing the modal frequencies to be predicted and crossdomain interactions to be modelled. A purpose-built electromechanical test platform is used to validate the model and demonstrate how electrical disturbances are passed through the generator to the mechanical system and affect the electrical network. Future research will use the test bed to demonstrate strategies for avoiding or suppressing unwanted interactions.
\end{abstract}

Keywords-Gearbox, vibration, electro-mechanical interaction, generator, aircraft, drivetrain model reduction

\section{INTRODUCTION}

The generator system described in this paper consists of a mechanical drivetrain transferring power through a series of shafts and gears from the prime mover to the electrical generator, which in turn supplies an electrical network. The drivetrain components have finite inertia and stiffness, forming a mechanical network with natural resonant modes, which is coupled through the generator to an electrical network with its own natural resonances. The electrical machine acts as the interface between domains to transfer useful power, but unwanted disturbances can also be passed between domains, exciting the resonant modes $[1,2]$. This electro-mechanical interaction can lead to accelerated aging of mechanical components [3, 4] and instability in electrical systems [1]. For example, electrical load variation is transferred through the generator as fast electrical torque disturbances, increasing

The authors are grateful to the EPSRC, Rolls-Royce plc, and the University of Manchester Alumni Fund for supporting this research. mechanical vibrations and causing speed fluctuations, which in turn pass back through the generator, affecting the electrical network. Single stand-alone generators can be very sensitive to perturbations on the electrical load, because in this layout the power system is inherently weak.

Electrical faults represent the worst case disturbance in [3], but longer duration lower amplitude load variation, such as phase imbalance can also contribute [3]. Modal analysis of an electro-mechanical wind power generator system, [5], predicts that increasing electrical voltage and reactive load reduce stability, and low speed operation provides lower system damping therefore being less stable. For a variable speed system [1], high powered, rapidly changing electrical loads at a low mechanical speed are considered the most problematic. If system-wide damping is insufficient, this can lead to sustained and damaging oscillations throughout the electro-mechanical network [1].

Multi-stage drivetrains exist in transport applications, for example to provide propulsion on automotive and marine systems, and electrical power generation for auxiliary loads on aircraft [6]. Interaction has been observed in a range of systems, for example sub-synchronous resonance in land based power generation [7,8] causing early fatigue of mechanical components [9], challenges for wind power generation [10, 11] causing gearbox failure [12], unpredicted faults in industrial processes such as mills [13], excessive vibration in electric and hybrid-electric vehicle drivetrains [2, 14] increasing wear [4], and wave induced instability in marine propulsion systems [15]. Methods for mitigating electro-mechanical interaction include minimising gearbox backlash [16], control scheme disturbance rejection [17] and repositioning of resonant modes through design [18]. However, the aero generator application discussed in this paper is particularly challenging. Weight constraints result in low stiffness shafts and very low levels of damping in a complex mechanical drivetrain and the electrical network is relatively weak with highly dynamic loads. The prime mover speed may vary over a range of greater than $2: 1$ and in some aircraft, the generator frequency also varies over a similar range [19].

Electrical and mechanical domains are often considered in isolation, and to properly understand and predict cross-domain interactions the electro-mechanical systems must be studied as a single system. [5] studies a drivetrain coupled with a generator in the frequency domain; a more complex mechanical system, using a generic generator with analysis in 
time and frequency domain is presented in [20]. Time domain analysis of a mechanical drivetrain with an asynchronous generator can be seen in [21]. The impact of the generator controller and its effects on drivetrain are studied in [22], analysing a flywheel, generator, and electrical power converter as a combined model. In general, the simulation of electromechanical networks is challenging, requiring multi-domain models, operating at very different time constants.

The key to preventing unwanted interaction is by designing the system so that resonant frequencies (in the drivetrain, electrical network and control system) are well separated from disturbance frequencies. Variable speed aircraft systems have disturbances over a wide range, and altering natural modes without adding mass is not easy. Significantly these strategies require a complete understanding of the behaviour of the electro-mechanical system, to identify both the dominant modal frequencies and-the components which produce them.

This paper presents a model-reduction strategy for an aircraft auxiliary power offtake to create a functional electromechanical simulation model which retains the physical representation of the drivetrain. The resonances of the full system are characterised in both the frequency and time domain, and the reduced order drivetrain model is validated against both the full model and measured test data. This process is repeated for a purpose-built $6.6 \mathrm{~kW}$ hardware test platform, in order to validate the modelling strategy. The paper demonstrates that transients in the electrical network can excite resonances in the mechanical network leading to a destabilised electrical network, and provides the insight to explain why this occurs, giving an ability to predict the resultant electromechanical interaction.

\section{AIRCRAFT ELECTRICAL POWER OFF-TAKE}

The aircraft electrical power off-take from the gas turbine prime mover consists of an extensive mechanical drivetrain delivering power to two electrical generators, and the electrical power network, as shown in Fig. 1. The mechanical drivetrain transmits power from a rotating spool in the gas turbine core, through a multi-stage accessory gearbox to the auxiliary loads, which include hydraulic and pneumatic pumps, and the electrical generators. The electrical generators (typically 2 per gas turbine) are controlled independently to provide standalone voltage regulation; these electrical networks are not paralleled for redundancy reasons [23]. A wide range of electrical loads exist on the network, which may be high powered, transient (e.g. actuators), pulsating (e.g. radar), or constant power (e.g. motor driven pumps)[23] with negative impedance gradients. These loads contribute to destabilising the electrical network and wider electro-mechanical system.

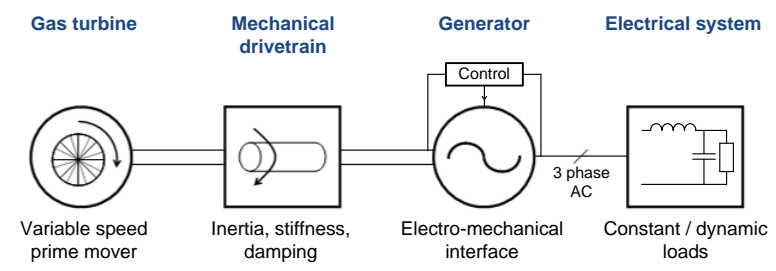

Fig. 1: Aircraft electro-mechanical system schematic
Electrical power demand on modern aircraft has risen approximately 2 fold in the last 20 years for civil aircraft [24], but is typically less than one percent of gas turbine output. For example the Rolls-Royce Trent 1000 [25] has a rated electrical offtake of approximately $1.1 \%$. It will grow again as manufactures move towards the all-electric airframe. Offtake, as a proportion of gas turbine output, can be higher still on noncivil aircraft. Higher electrical power demand has led to an increased power rating of electrical generators, meaning that high power disturbances are now passed on to the flight-critical drivetrain. Spool-mounted 'embedded' generators have also been considered [26] [27]. Direct coupling to the prime mover eliminates the drivetrain, but torque disturbances arising from changes in power flow in the electrical network are imposed directly onto the spool, potentially interfering with engine control, thus still requiring good understanding of the full electro-mechanical system. Generally the gas turbine controller has a time constant an order of magnitude lower than disturbance and resonant frequencies making it robust to electro-mechanical interaction. The flight critical drivetrain, however, is susceptible to these affects.

\section{MEChanical Drivetrain MODELling}

A high fidelity spring-mass-damper representation of the drivetrain was initially developed as shown in Fig. 2. Offtake from the spool is transferred to the externally mounted, parallel axis, accessory gearbox by the radial driveshaft and angular driveshaft, together here referred to as the transmission. To minimise the impact on propulsion, the transmission shafts have a narrow diameter resulting in low torsional stiffness. The auxiliary load provides the interface between the mechanical network and hydraulic, pneumatic, and electrical networks and includes the fuel pump, hydraulic pump, and electrical generators which are each coupled to the auxiliary gearbox by a drive shaft. The drivetrain has low levels of damping so as to maximise its efficiency.

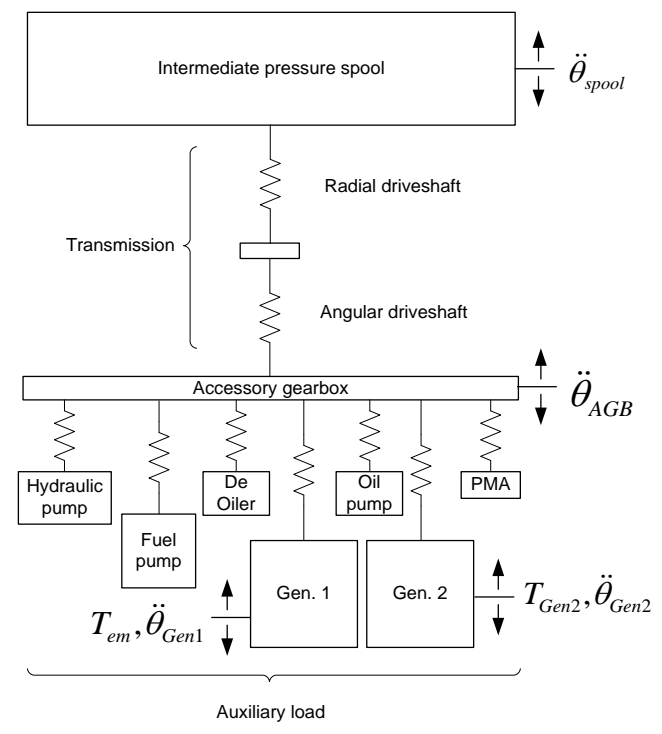

Fig. 2: Spring mass representation of the aircraft mechanical drivetrain

The full drivetrain model was developed in Mathworks Simulink using the SimDriveline blocksets. The model 
represents torsional elements by inertia, stiffness, and a damping model, giving the model 9 degrees of freedom. Model parameters were obtained from design data. This full model is too complex, in practise, for use as part of an electromechanical simulation but allows the drivetrain to be characterised.

\section{A. Frequency domain analysis}

A frequency sweep was carried out by simulating a sinusoidal electro-magnetic disturbance torque at generator 1 , over a range from $1 \mathrm{~Hz}$ to $140 \mathrm{~Hz}$ with a resolution of $0.1 \mathrm{~Hz}$ and magnitude of $1 \mathrm{Nm}$ peak. All other components were modelled at typical speeds and loads. A previous full range frequency sweep at a lower resolution detected no modes above $140 \mathrm{~Hz}$. The frequency domain data for components throughout the drivetrain is shown in Fig. 3. Three low order modes can be identified, a $1^{\text {st }}$ mode, at $26.6 \mathrm{~Hz}$, appears throughout the drivetrain, a $2^{\text {nd }}$ mode, at $37.2 \mathrm{~Hz}$, is detected only in the electrical generators and components coupling them. The $3^{\text {rd }}$ mode is also seen, at $87.2 \mathrm{~Hz}$, throughout the drivetrain but at a consistently lower amplitude than the other modes. No modes are identified at the hydraulic pump. These modes represent the key behaviour of the drivetrain and are summarised in

Table 1.

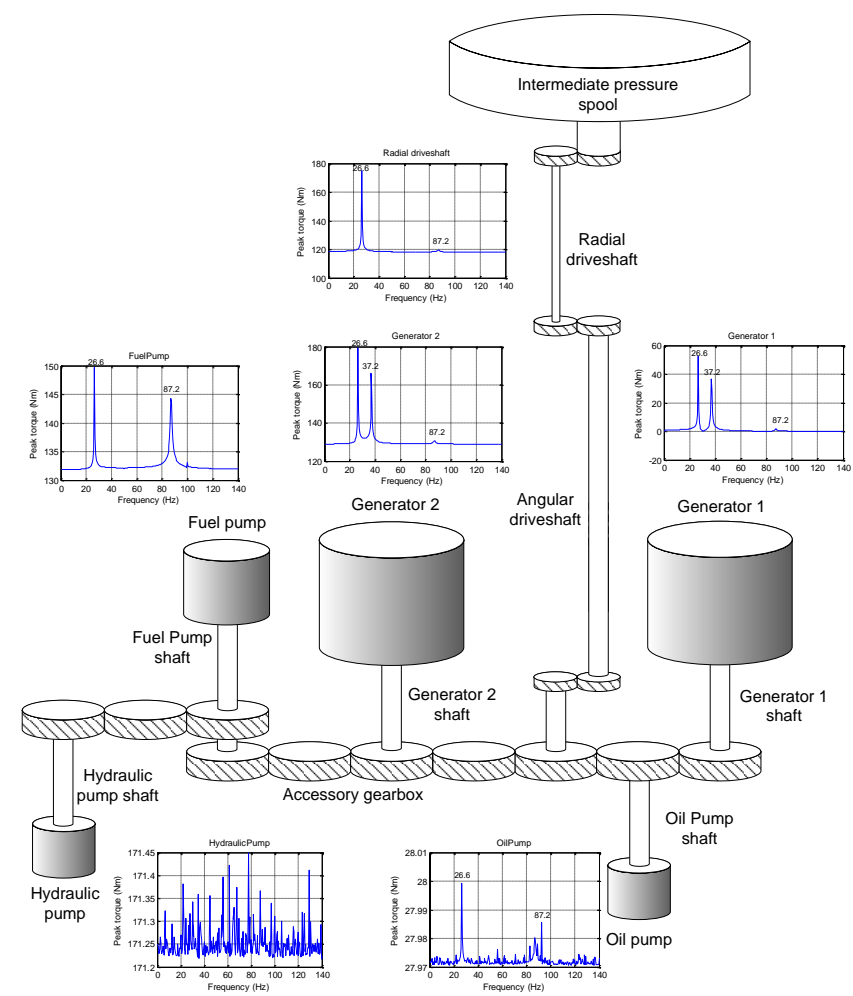

Fig. 3: Full definition drivetrain model, frequency sweep torque response
TABLE 1: FULL DRIVETRAIN MODEL, LOW ORDER RESONANT FREQUENCIES

\begin{tabular}{|l|l|l|l|}
\cline { 2 - 4 } \multicolumn{1}{c|}{} & \multicolumn{3}{c|}{ Frequency (Hz) } \\
\hline Component & \multicolumn{1}{c|}{$\boldsymbol{1}^{\text {st }}$ mode } & \multicolumn{1}{c|}{$\mathbf{2}^{\text {nd }}$ mode } & $\mathbf{3}^{\text {rd }}$ mode \\
\hline Spool & - & - & - \\
\hline Transmission & 26.6 & - & 87.2 \\
\hline Generator 1 & 26.6 & 37.2 & 87.2 \\
\hline Oil Pump & 26.6 & - & 87.2 \\
\hline Generator 2 & 26.6 & 37.2 & 87.2 \\
\hline Fuel Pump & 26.6 & - & 87.2 \\
\hline
\end{tabular}

\section{B. Time domain analysis}

In order to understand the development of the 3 low order modes identified, torque was compared at each node for the three modal frequencies. The time domain results are shown in Fig. 4. Note, the modes are reproduced to the nearest $0.5 \mathrm{~Hz}$.

The $1^{\text {st }}$ mode (Fig. 4 (a)) shows the entire drivetrain acting in-phase and is produced by the combined inertia of the auxiliary loads oscillating against the spool, though the transmission. This represents a fixed-free system [28]. The $2^{\text {nd }}$ mode (Fig. 4 (b)) is dominated by an out-of phase relationship involving only the two generators. As the generators and coupling shafts are identical, oscillations develop which do not spread further throughout the drivetrain. This represents a freefree system [29]. The $3^{\text {rd }}$ mode (Fig. 4 (c)) has the generators in phase with one another, but out of phase with the fuel pump and transmission. This indicates a vibration between the two generators and the inertia of the fuel pump.
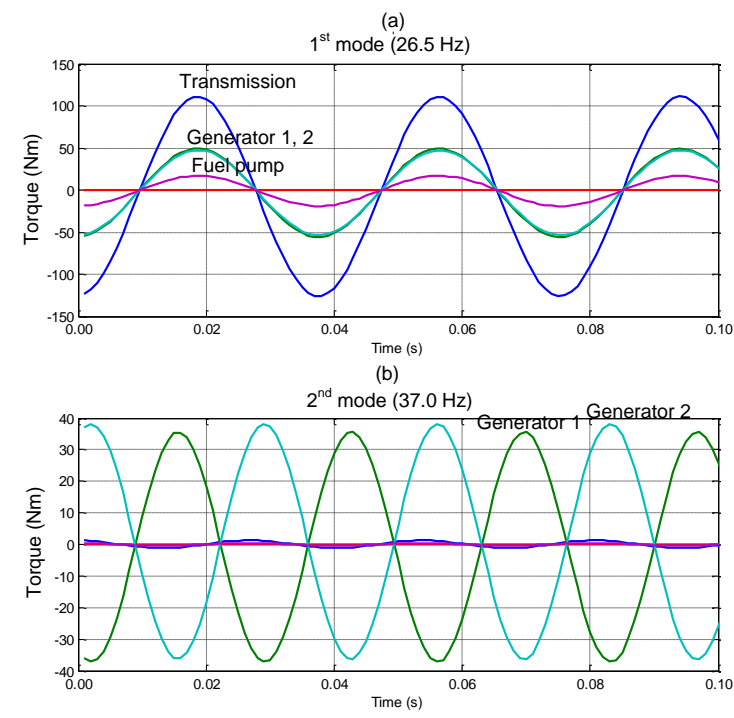

Time

$3^{\text {rd }} \operatorname{mode}(87.0 \mathrm{~Hz})$

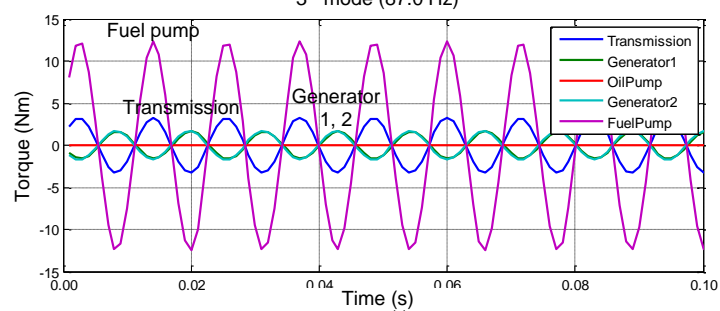


Fig. 4: Full definition drivetrain model, time domain model response at: $1^{\text {st }}$ mode (a), $2^{\text {nd }}$ mode (b), $3^{\text {rd }}$ mode (c)

With the drivetrain operating at $50 \%$ speed and a baseload of 0.2 p.u., an electromagnetic load equivalent to 0.4 p.u. is simulated at generator 1 , generator 2 has a constant nominal load of 0.3 p.u.. The resultant shaft torque is shown in Fig. 5(a) and a time windowed FFT of the torque is shown in Fig. 5(b). The electromagnetic load step, at 1s, creates oscillations in the drivetrain which decay slowly due to the low levels of damping. The time windowed FFT shows no frequencies present before the load step and that in the second after the load step the $1^{\text {st }}, 2^{\text {nd }}$, and $3^{\text {rd }}$ mode can be seen, with the $3^{\text {rd }}$ mode at a significantly lower amplitude. In the seconds after the electrical load step the oscillations decay with the $3^{\text {rd }}$ mode showing the highest modal damping.
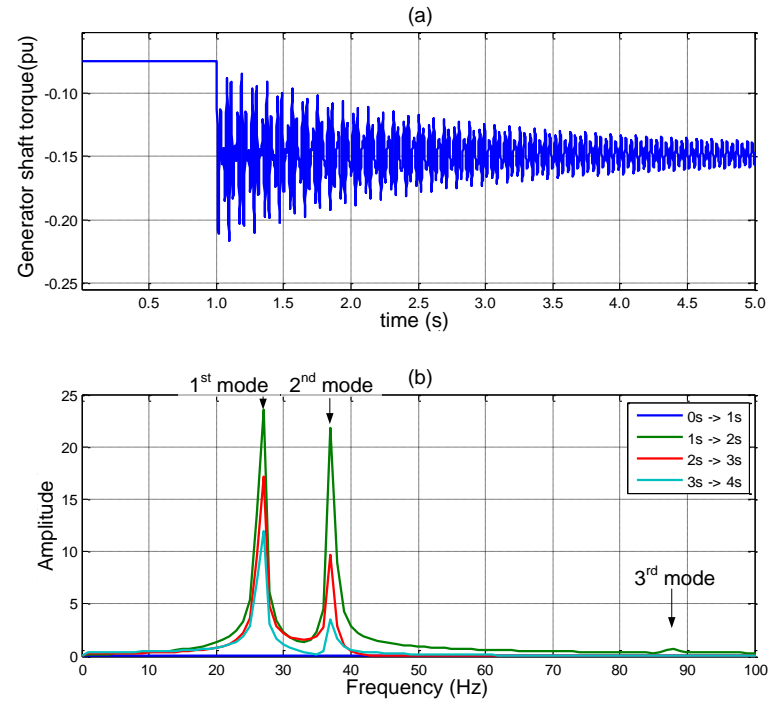

Fig. 5: Full definition drivetrain model, time domain model response to a simulated electromagnetic load step from generator 1: time response (a), FFT in three subsequent time windows (b)

\section{DRIVETRAIN MODEL REDUCTION}

The parameter ratios and symmetries shown are typical of aircraft generator systems, and lend themselves well to the conclusions presented in Section III regarding the role of drivetrain components on dominant modes. This understanding allows a direct and physical modelling approach to be used for drivetrain model reduction, instead of the systematic but less intuitive modal approach based on the diagonalization of the full-order mass and stiffness matrices.

The time domain modal responses shown in Fig. 4 indicate that the behaviour of the drive train is dominated by components with the most significant inertia or stiffness, and so insignificant elements can be neglected. Speed-referred values must be considered, as speed is not constant throughout the drivetrain. The inertia and stiffness of a component was identified as significant if it was 5 times greater or lower, respectively, than other elements in the drivetrain. This is initially an asumption which is demonstrated to be accurate by this, and ongoing, research. Adjacent stiffness or inertia values were then combined (Fig. 6), before a further stage of reduction was carried out. The reduced-order, lumped-parameter model
(Fig. 7) retains the generators, transmission shafts and generator shafts, and treats the spool as a mechanical ground. It allows the modes to be derived analytically.

Drivetrain resonant frequencies are not detected in the spool, as can be seen in

Table 1. This indicates that the inertia of the spool is sufficiently large to make it insensitive to disturbances from the drivetrain, and will not contribute to resonance. The drivetrain can therefore be modelled as speed stiff, greatly reducing the solve time. Analysis of drivetrain data shows that the spool inertia is approximatly 60 times greater than the sum of the inertia of all other drivetrain components.

The two electrical generators and the fuel pump are identified as dominant inertias, but with very high stiffness. The radial driveshaft and angular driveshaft of the transmission as well as the connecting driveshafts of the loads represent the dominant stiffness components, although their inertia is insignificant. Other components represent less significant inertia and stiffness values and are can therefore be neglected or combined with adjacent components, to form the simplified drivetrain model shown in Fig. 6. Where two significant components are coupled their parameters are amalgamated, as with the transmission shafts. The accessory gearbox is included at this stage as it provides the coupling between transmission and accessory load.

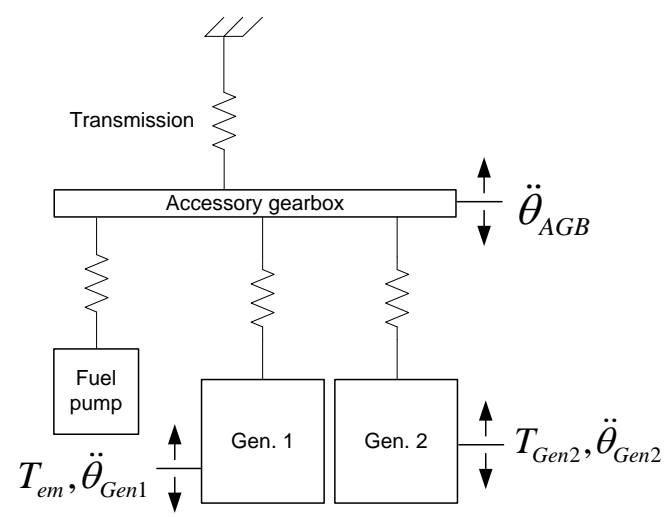

Fig. 6: Spring mass representation of partially reduced drivetrain model, with only key components.

A final further drivetrain reduction stage is carried out in order to simplify the analysis. Although large compared to other drivetrain components the fuel pump and accessory gearbox have very low inertia compared to the generators and are therefore neglected. The removal of the fuel pump, and associated gearing, from the model means that the $3^{\text {rd }}$ mode is no longer represented, so disturbances affecting this frequency cannot be considered. However, the low amplitude of the mode in comparison to the $1^{\text {st }}$ and $2^{\text {nd }}$ modes makes this an acceptable approximation and improves the focus on the more significant modes. This system was modelled in Simulink using the SimDriveline blocksets. Finally, the accessory gearbox is modelled as ideal with speed referred values of inertia and stiffness used for both generators. The simplified, reducedorder, drivetrain model is shown in Fig. 7. 


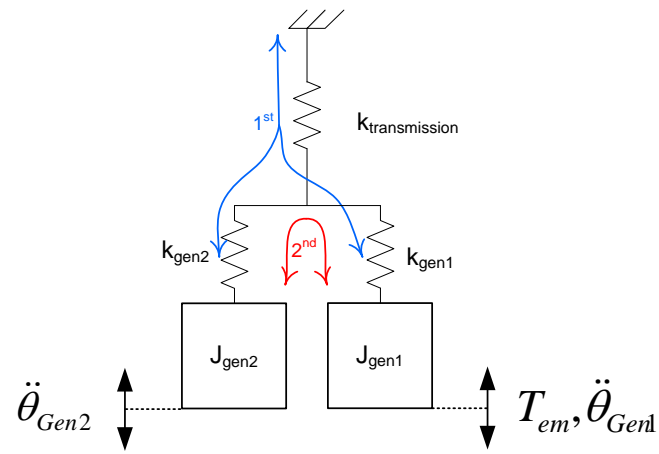

Fig. 7: Spring mass representation of lumped parameter aircraft drivetrain model with operation of $1^{\text {st }}$ mode and $2^{\text {nd }}$ mode

For validation of the reduced order model against the full drivetrain model, an electrical load step is applied corresponding to a step from $0.2 \mathrm{pu}$ to $0.4 \mathrm{pu}$ at 1 second, the resultant generator shaft torque in the time and frequency domains are shown in Fig. 8.
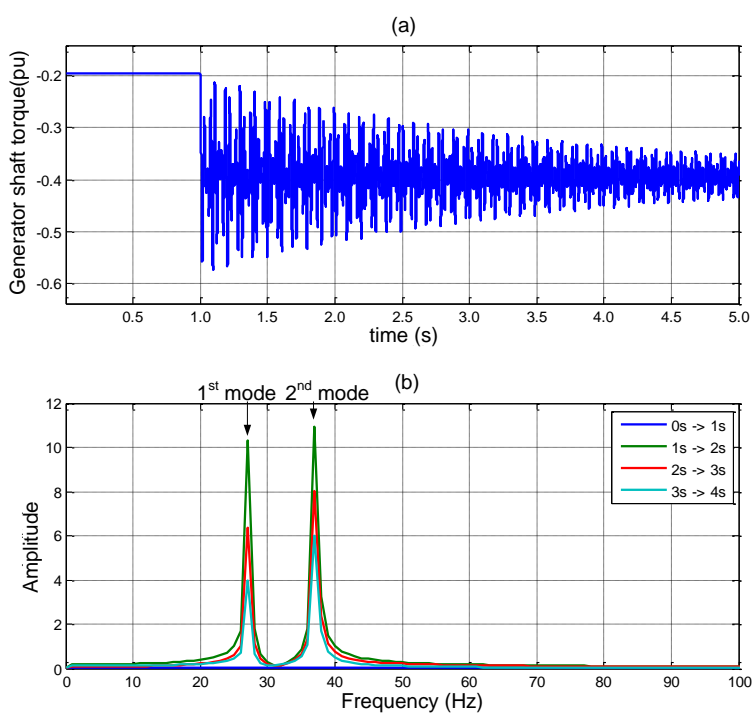

Fig. 8: Reduced order drivetrain model, time domain model response to electrical load step from generator 1: time response (a), FFT in three subsequent time windows (b)

Damping levels are seen to be similar between the full and reduced order model as the decay of the $1^{\text {st }}$ and $2^{\text {nd }}$ modes happen at a similar rate overall. Damping in the $2^{\text {nd }}$ mode is appears slightly higher than for the $1^{\text {st }}$ mode, this is reversed in the full drivetrain model Fig. 5.

\section{A. Identification of modes in reduced order model}

The significant model reduction allows the $1^{\text {st }}$ and $2^{\text {nd }}$ modes to be determined analytically using the combined parameters and the equations for natural resonance of a fixedfree [28] and free-free [29] mechanical system as given in (1) and (2), respectively.

$$
\omega_{n_{-} \text {fixed }}=\sqrt{\frac{k_{\text {fixed }}}{J_{\text {fixed }}}}
$$

$$
\omega_{n_{-} \text {free }}=\sqrt{k_{12} \cdot\left(\frac{1}{J_{1}}+\frac{1}{J_{2}}\right)}
$$

where: $\omega_{n}=$ Natural angular frequency of resonance, $k=$ torsional stiffness, $J=$ inertia

The 1st and 2nd modes are calculated as $27.90 \mathrm{~Hz}$ and $37.22 \mathrm{~Hz}$ respectively. The $1 \mathrm{st}$ mode has generators operating in-phase and so the inertia is the sum of the two generators (3) and torsional stiffness is the sum of the generator shaft stiffness in parallel and the transmission stiffness (4). The 2 nd mode has the generators acting out of phase with no action on the transmission, the generator drive stiffness is summed (5).

$$
\begin{gathered}
J_{1 s t_{-} \bmod e}=J_{\text {gen } 1}+J_{g e n 2} \\
1 / k_{1 s t_{-} \bmod e}=1 /\left(k_{g e n 1}+k_{g e n 2}\right)+1 / k_{\text {transmission }} \\
1 / k_{2 n d_{-} \bmod e}=1 / k_{\text {gen } 1}+1 / k_{\text {gen } 2}
\end{gathered}
$$

A frequency sweep is undertaken on the reduced order drivetrain model. This is achieved in an identical fashion to that carried out in the full drivetrain model, by a simulated $1 \mathrm{Nm}$ torque disturbance at generator 1 , and with a range of $1 \mathrm{~Hz}$ to $140 \mathrm{~Hz}$ and a resolution of $0.1 \mathrm{~Hz}$. The 1 st and 2 nd modes are identified at $26.5 \mathrm{~Hz}$ and $37.0 \mathrm{~Hz}$ respectively, no other modes are seen.

Table 2 summarises the low order modes identified in the test data, full drivetrain model and reduced order model (determined both analytically and through frequency sweep).

Table 2: Low order modes in test data, full definition drivetrain model, and lumped parameter drivetrain model

\begin{tabular}{|l|l|l|l|}
\cline { 2 - 4 } \multicolumn{1}{c|}{} & \multicolumn{3}{c|}{ Mrequency (Hz) } \\
\hline Model & \multicolumn{1}{c|}{$\mathbf{1}^{\text {st }}$ mode } & $2^{\text {nd }}$ mode & $\mathbf{3}^{\text {rd }}$ mode \\
\hline Engine test data & 25.8 & 35.5 & - \\
\hline $\begin{array}{l}\text { Full definition model } \\
\text { (frequency sweep) }\end{array}$ & 26.6 & 37.2 & 87.2 \\
\hline $\begin{array}{l}\text { Reduced order model } \\
\text { (frequency sweep) }\end{array}$ & 26.5 & 37.0 & - \\
\hline $\begin{array}{l}\text { Reduced order model } \\
\text { (lumped analysis) }\end{array}$ & 27.90 & 37.22 & - \\
\hline
\end{tabular}

The full definition drivetrain model replicates the $1^{\text {st }}$ and $2^{\text {nd }}$ mode within $0.8 \mathrm{~Hz}$ and $1.7 \mathrm{~Hz}$ respectively, a $3^{\text {rd }}$ mode is also seen at low amplitude. The $3^{\text {rd }}$ mode is not detected in the test data. It is suspected that damping levels are higher than in the simulated system and that the frequency detection methods used lack the necessary sensitivity. The reduced order model only represents the $1^{\text {st }}$ and $2^{\text {nd }}$ modes, but they are found to be within $1.5 \mathrm{~Hz}$ of both the full drivetrain model and test data, giving credibility to the model reduction strategy. There is a small difference in frequency for modes identified in the reduced order model by analytical methods and the frequency sweep due to the presence of a small gearbox inertia. 


\section{ELECTRO-MECHANICAL TEST PLATFORM}

A scaled electro-mechanical drivetrain test platform has been designed and built, as shown in Fig. 9. The aim of the experimental work is to validate the mechanical modelling work, predicting resonant modes, and to demonstrate how these resonances can be triggered by electrical disturbances. Future work will then use the platform to test strategies for reducing unwanted interactions or mitigating their effects.

Drive is provided by a DC machine, and a $118 \mathrm{~kg}, 7 \mathrm{~kg} . \mathrm{m}^{2}$, flywheel simulates the inertia of the gas turbine spool. The spool dynamics could be entirely emulated with a suitably rated drive machine as described in [20], however this method has a limited bandwidth and requires a carefully designed compensator.

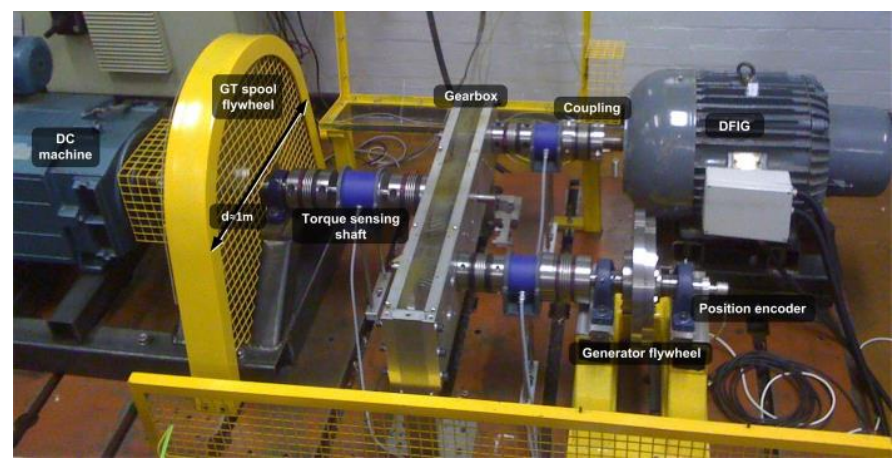

Fig. 9: Electro-mechanical drivetrain test platform photograph

Drive shafts are instrumented with torque transducers and rotary position encoders are attached to the high inertia components to monitor torsional vibration. The test platform includes a doubly-fed induction generator (DFIG), complete with rotor-side converter, controlled to achieve voltage and frequency regulation across a speed range of 600rpm to $1400 \mathrm{rpm}$ on the generator side, the parallel axis gearbox has a drive ratio of $1.5: 1$. A DFIG is chosen for the generator because it provides a way of decoupling electrical frequency from mechanical drive speed, this is discussed in [19], along with further details of the generator control scheme. Connections to the DFIG rotor give the machine fast dynamics, allowing control schemes to be developed to mitigate interaction. The machine rotor-side is fed via a commercial inverter, the stator side terminals supply a standalone electrical network, loading is provided by a resistive load bank. A fieldorientated control scheme is implemented to provide standalone voltage $\left(215 \mathrm{~V}_{\mathrm{rms}}\right)$ and frequency $(50 \mathrm{~Hz})$ regulation, with cascaded current and voltage control loops, this is described in more detail in [19]. The second, identical, electrical generator is represented by a flywheel wheel with matched inertia and coupling stiffness. The test platform is scaled with power and frequency and designed to have resonant modes at $13 \mathrm{~Hz}$ and $22 \mathrm{~Hz}$.

A diagram of the test platform is given in Fig. 10, showing the positioning of torque, position, voltage and current sensors, as well as the control schemes used to emulate the gas turbine spool and provide variable speed voltage regulation on the generator. The fuel pump shown in this diagram is not implemented for results presented in this paper.

\section{A. Mechanical characterisation}

A torque impulse, or hammer test, determines mechanical resonance by observing the free oscillation of a component after a torque impulse is applied. The test characterises the drivetrain in isolation so as to identify and confirm the frequency of resonance modes. It also provides a means of observing damping levels from the rate at which the torque oscillations decay. Non-linearity (backlash) within the gearbox prevents an impulse from triggering the oscillations at the $1^{\text {st }}$ mode. The gearbox is locked (by a wooden wedge) and an impulse torque provided at the generator, the torque sensing on the shaft is used to record the resulting torque oscillation in the time domain, before the data is post-processed into the frequency domain, using an FFT applied over the 1s window from the start of the transient. Example test data is shown in Fig. 11. The test is also repeated for the generator flywheel shaft.

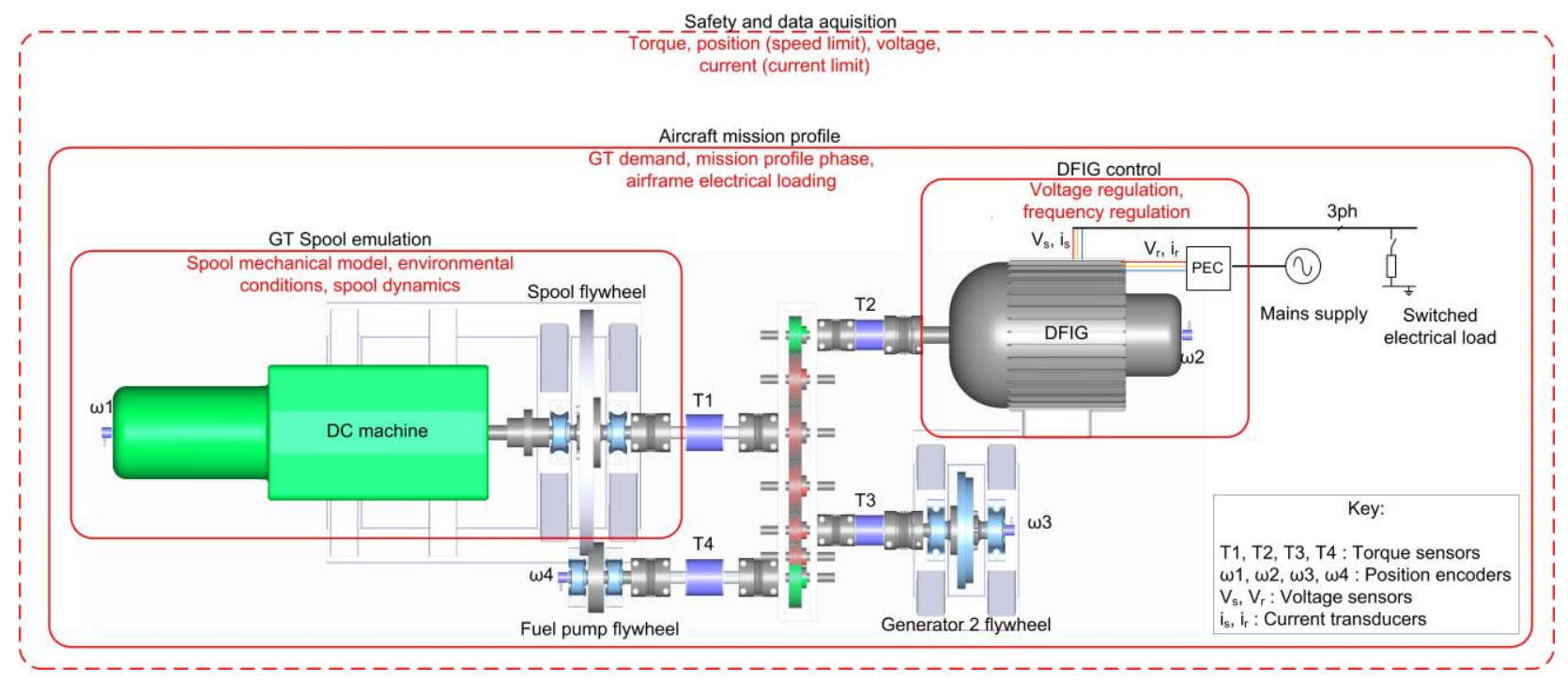

Fig. 10: Test platform and control scheme diagram 

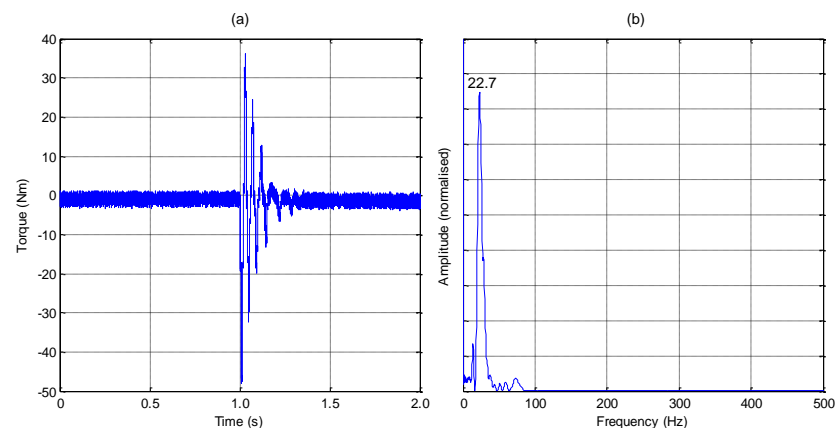

Fig. 11: Torque impulse test example, time domain (a) and frequency domain (b)

The results show an initial torque oscillation between the locked gearbox and the free generator inertia in response to a torque impulse at the generator. The oscillations decay within $0.3 \mathrm{~s}$, approximately 10 times faster than shown in aircraft test data, indicating higher levels of damping. The hammer test results are used to confirm that the two generator shafts stiffness and inertia are identical and that they have a natural resonance of $22.7 \mathrm{~Hz}$. Locking the gearbox in this way excludes the inertia and stiffness of the gears coupling the generators, however their values are considered insignificant in comparison to that of the generator and shaft. Oscillation of the fixed-free generator and shaft occur at the same frequency as the free-free oscillation between the two generators which creates the $2^{\text {nd }}$ mode.

In order for the $1^{\text {st }}$ mode to be identified, the gearbox must be continually engaged, this is achieved by providing an electrical load of approximately $2 \mathrm{~kW}$ on the generator while drive is provided through the DC machine. The generator dq control scheme is altered to provide a $5 \mathrm{~A}$ peak sinusoidal disturbance on the q-axis rotor current control loop. This demonstrates the transfer of disturbances from the electrical network to the mechanical drivetrain through the generator. In this way a frequency sweep is carried out with a resolution of $1 \mathrm{~Hz}$ over a range from $6 \mathrm{~Hz}$ to $25 \mathrm{~Hz}$, it is repeated for two different drive speeds, 930rpm and 1000rpm. The peak shaft torque on the generator flywheel, at each disturbance frequency, is shown in Fig. 12.

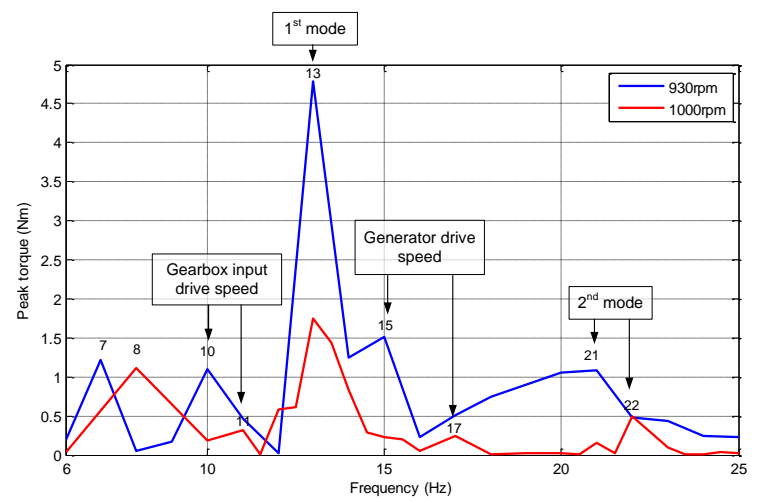

Fig. 12: Test platform frequency sweep, generator flywheel torque at $930 \mathrm{rpm}$ and $1000 \mathrm{rpm}$
In both results the drive speed can be identified from the once per revolution disturbance, at $15 \mathrm{~Hz}$ and $17 \mathrm{~Hz}$, for $930 \mathrm{rpm}$ and 1000rpm, respectively. The input gearbox drive speed can also be identified, and is scaled by the gear ratio of $1: 1.5$, at $10 \mathrm{~Hz}$ and $11 \mathrm{~Hz}$ accordingly. The dominant resonance in both cases is at $13 \mathrm{~Hz}$, and is identified as the drivetrain $1^{\text {st }}$ mode. The $2^{\text {nd }}$ mode can also be identified, albeit at a lower amplitude between $21 \mathrm{~Hz}$ and $22 \mathrm{~Hz}$. A further resonance is noted at between $7 \mathrm{~Hz}$ and $8 \mathrm{~Hz}$, this isn't a designed torsional resonance but is assumed to be a bedplate vibration.

The frequencies identified in the test platform by the hammer test and frequency sweep are summarised in Table 3. Drivetrain characterisation on the test platform, using a range of tests, identifies torsional resonance close to the designed $1^{\text {st }}$ and $2^{\text {nd }}$ modes. Other low frequency resonances are identified by the frequency sweep although these are not close to either of the designed modes.

Table 3: Resonance identified in the test platform

\begin{tabular}{|l|l|l|l|}
\cline { 2 - 4 } \multicolumn{1}{c|}{} & \multicolumn{3}{c|}{ Frequency $(\mathrm{Hz})$} \\
\hline Test & \multicolumn{1}{c|}{$\mathbf{1}^{\text {st }}$ mode } & $2^{\text {nd }}$ mode & \multicolumn{1}{c|}{ Other } \\
\hline Design & 13 & 22 & - \\
\hline Hammer test & - & 22.7 & - \\
\hline $\begin{array}{l}\text { Electro-mechancial } \\
\text { frequency sweep }\end{array}$ & 13 & $21-22$ & $7-8$ \\
\hline
\end{tabular}

\section{B. Electrically induced drivetrain oscillations}

Having verified the resonant modes, the transfer of electrical disturbance through the generator to induce mechanical resonance, is now considered.

The test platform is operated with the electrical generator open circuit. At $1.0 \mathrm{~s}$ an electrical load of $30 \Omega$ per phase is applied, generating an electrical load step, generator shaft torque is recorded and analysed in frequency domain at 3 time windows, as shown in Fig. 13 for a drive speed of 650rpm.

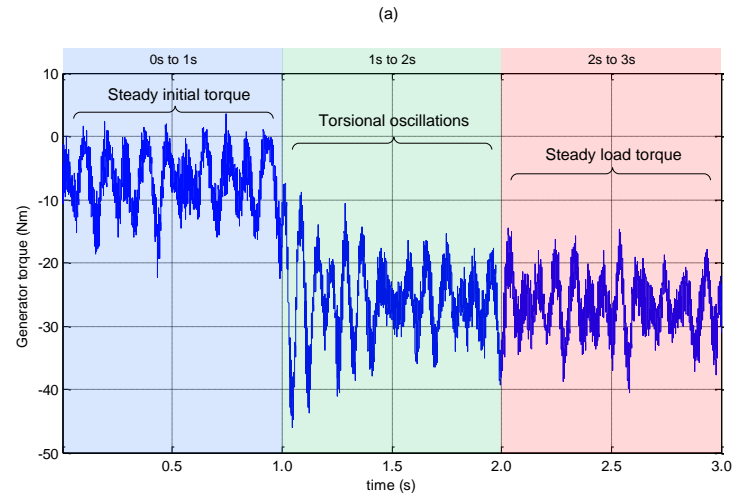



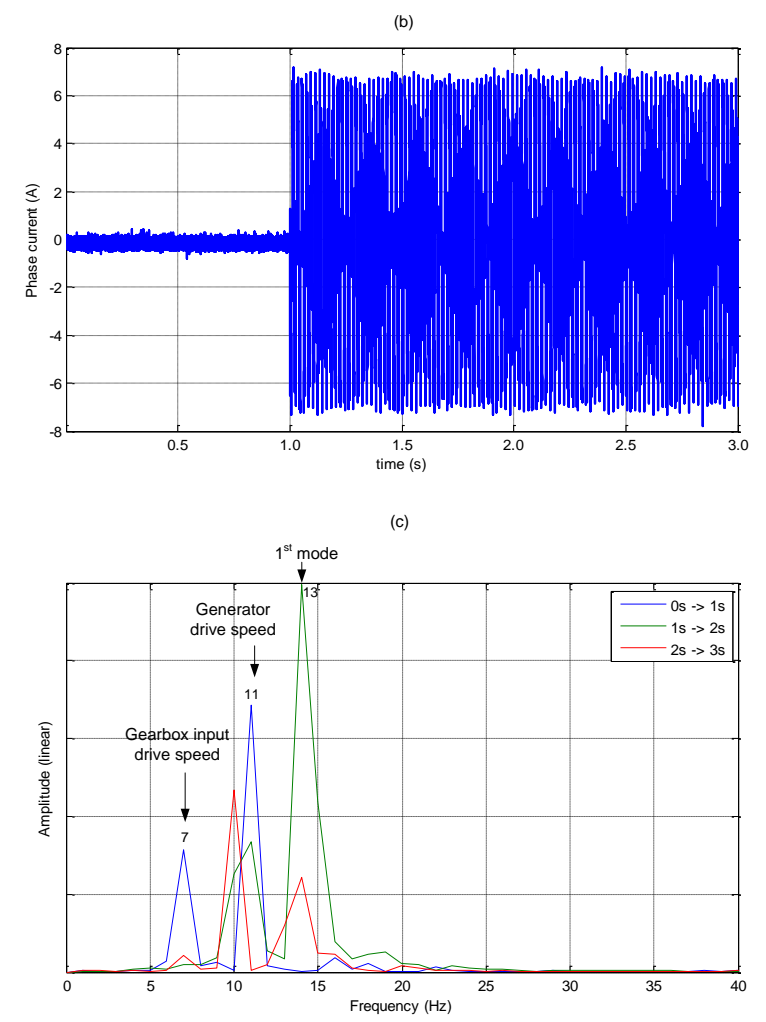

Fig. 13: Test platform electrical load step at 650rpm - generator shaft torque, time domain response (a), phase rotor current (b), and time windowed frequency domain (c)

Fig. 13(b) shows a single phase current, it can be seen to rise to approximately $7 \mathrm{~A}$ peak at $1 \mathrm{~s}$ and in this instance remains well regulated at $50 \mathrm{~Hz}$. The time domain generator shaft torque is shown in Fig. 13(a); between 0 and 1s a steady torque with disturbance can be seen, when the electrical load has increased at $1 \mathrm{~s}$ the torque increases due to the change in power demand and an oscillation can be seen which decays after approximately $0.5 \mathrm{~s}$. Between $2.0 \mathrm{~s}$ and $3.0 \mathrm{~s}$ a steady torque is seen, again with disturbance. Data from a time windowed FFT is shown in Fig. 13(c), data has been normalised to the peak $1^{\text {st }}$ mode disturbance, the drive speed $(11 \mathrm{~Hz})$ and gearbox input speed $(7 \mathrm{~Hz})$ are visible across the time windows, a frequency at $13 \mathrm{~Hz}$ is seen only during the $1 \mathrm{~s}$ to $2 \mathrm{~s}$ time window, the point at which the torsional oscillation is seen in the time domain, this occurs at the $1^{\text {st }}$ mode frequency.

For robustness this electro-mechanical load step is repeated at an alternative drive speed of $1400 \mathrm{rpm}$. The electrical load step is again applied at $1 \mathrm{~s}$ with the same time windows considered for FFT, shown in Fig. 14.

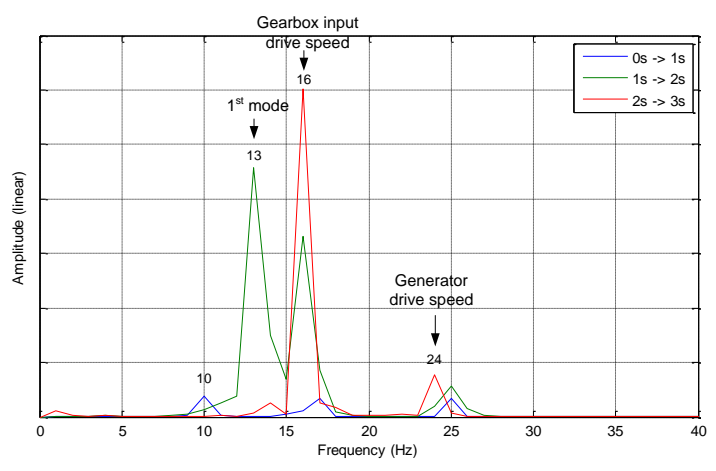

Fig. 14: Test platform electrical load step at 1400rpm - generator shaft torque time windowed frequency domain

Again, data has been normalised to the peak $1^{\text {st }}$ mode disturbance. The generator drive speed $(24 \mathrm{~Hz})$, as well as the gearbox input speed $(16 \mathrm{~Hz})$ can again be seen in multiple time windows. A strong response at $13 \mathrm{~Hz}$ is seen only in the time window immediately after the electrical load step, with a frequency corresponding to the $1^{\text {st }}$ mode. Electrical load steps are shown to induce mechanical vibration within the test platform and are clearly identifiable at the $1^{\text {st }}$ model frequency of $13 \mathrm{~Hz}$. The $2^{\text {nd }}$ mode is not clearly seen with these tests. Aircraft generators are variable speed, constant power systems and so for a given electrical load step the torque magnitude, and so drivetrain disturbance, will be largest at the lowest drive speed. At this low drive speed the gas turbine offtake margin is potentially also at its highest.

Fig. 15 shows the machine phase current (b) and voltage (a) when an electrical load of $2.7 \mathrm{~kW}$ is applied at $1.0 \mathrm{~s}$. The current appears initially well regulated, but by $1.1 \mathrm{~s}$ a disturbance develops and is sustained resulting in poor power regulation on the electrical network. This demonstrates interaction and shows the importance of controller design in its mitigation.
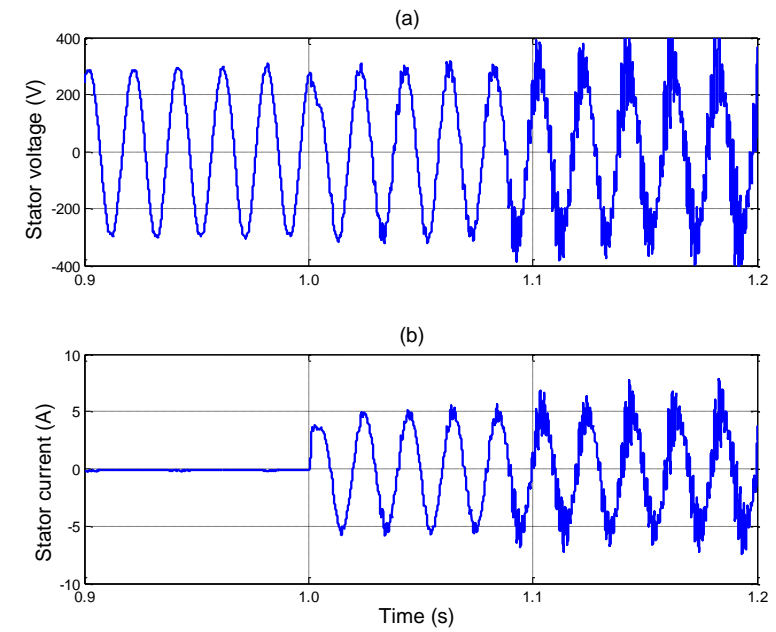

Fig. 15: Test platform electrical load step at $1400 \mathrm{rpm}$ - generator voltage (a) and phase current (b) 


\section{ELECTRICALLY INDUCED SUSTAINED TORSIONAL OSCILLATION}

The electro-mechanical model, with reduced order drivetrain, has been validated against the test platform, and is now used to simulate more challenging electrical loads, which may damage the hardware. The generator is represented by a standard fourth-order model, the DFIG on the test platform has been characterised to provide the machine parameters and is discussed in [19]. A field-orientated controller has been implemented to provide standalone voltage $\left(215 \mathrm{~V}_{\mathrm{rms}}\right)$ and frequency $(50 \mathrm{~Hz})$ regulation. The controller comprises an inner current control loop and an outer voltage control loop. The current control has a bandwidth of approximately $1000 \mathrm{~Hz}$. A low amplitude pulsating electrical load, such as radar, is emulated by a switched resistive load at approximately $5 \mathrm{~Hz}$.
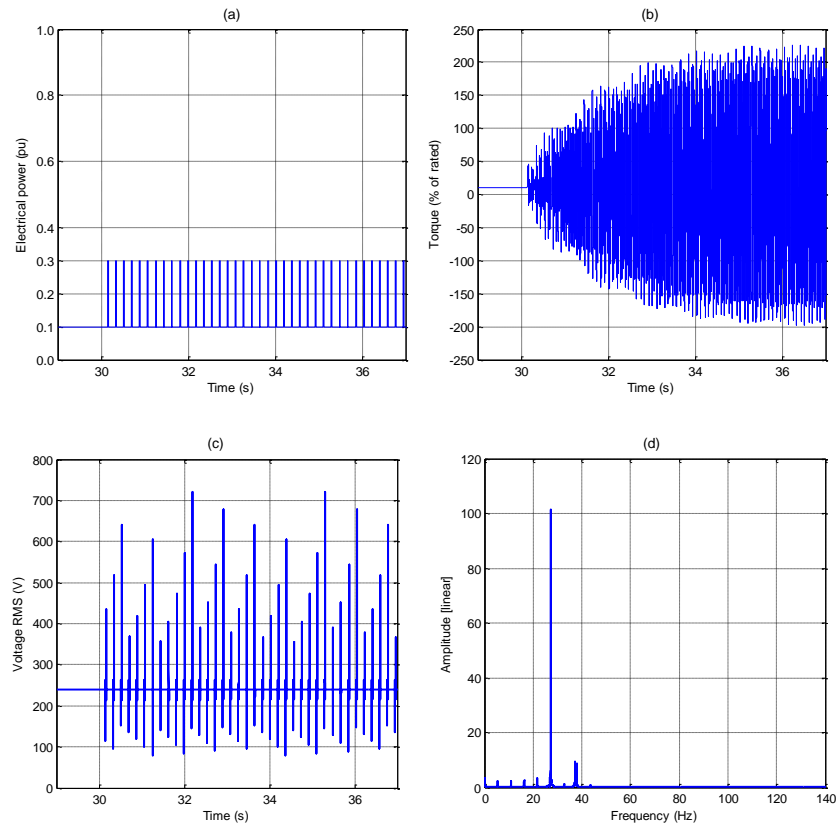

Fig. 16: Simulated pulsating electrical load (a), generator shaft torque showing sustained torsional oscillation (b), generator voltage (c), frequency content of torsional oscillation $(\mathrm{d})$

Fig. 16 (a) shows the power corresponding to a resistive stand-alone load. A steady generator shaft torque is seen until the pulsating load is activated at $30 \mathrm{~s}$. At this point torque oscillations develop, and grow to in excess of twice the rated torque of the gearbox by $36 \mathrm{~s}$, despite the low rating of the electrical load. High transient voltage can be seen in the electrical network with the potential to damage connected electrical systems. Voltage transients above $700 \mathrm{~V}_{\text {rms }}$ and below $100 \mathrm{~V}_{\text {rms }}$ are seen, the positive transient exceeds the shortest duration peak transient $(+32 \%)$ prescribed for low frequency aircraft power systems in [30]. In a practical application, the pulsed load would be fitted with an input filter to suppress the high voltage spikes and ensure compliance with the voltage standard. The frequency content of the torsional oscillation demonstrates that the modes are excited by harmonic components of the pulsed electrical load. Such a sustained torsional oscillation will result in accelerated wear for the drivetrain, in particular the gearbox, and a high chance of instability in the electrical network. Although the pulsating load is at low amplitude its frequency is a close integer multiple of drivetrain resonances (at $27 \mathrm{~Hz}$ and $37 \mathrm{~Hz}$ ).

The torque oscillations, shown in Fig. 16(b), are the result of drivetrain resonances. Voltage oscillations, shown in Fig. 16(c) are due to excitation of the generator controller. This was confirmed by re-running the simulation with a speed stiff generator model, partially decoupling the electro-mechanical system. Similar voltage oscillations appear but with a slightly lower amplitude, showing that both torque and voltage oscillations appear independently but are reinforced by the electro-mechanical interaction

Significantly it is found that electrical loading should avoid resonant frequencies in the mechanical domains if the effects of interaction are to be avoided. Alternatively, passive or active damping must be added to the electro-mechanical system in order for a load such as this to be operated reliably. However, passive damping adds mass and/or inefficiency to the electrical and mechanical domains. Active filtering in the generator controller can limit the transfer of disturbances between domains at critical frequencies but may also impair power quality on the electrical network, if not implemented carefully. For this reason, a thorough knowledge of system wide resonances is needed for such a controller to be implemented. An adaptive controller technique is implemented in simulation only in [31]. In [22] a control strategy is implemented for the reduction of the oscillations in an electro-mechanical system. Electrical network resilience can also be increased by integrated control of the various converters or by paralleling multiple generators, a strategy not favoured by aircraft designers.

\section{CONCLUSION}

Results presented in this paper demonstrate an ability to predict the occurrence of electro-mechanical interaction in systems with complex mechanical drivetrains. The drivetrain model is reduced from 9 to 2 degrees of freedom and replicates key modes to within $5 \%$ of their measured frequency. The behaviour of these torsional models is investigated in detail to understand their development. A purpose-built $6.6 \mathrm{~kW}$ electromechanical test platform is able to replicate these resonant modes, and several results are presented which validate the modelling strategy. Electrical load variation is shown to trigger mechanical variations in both the model and test hardware, this interaction between the mechanical and electrical networks may have destabilising results. Disturbances in both the drivetrain and electrical power network are shown. Sustained torsional oscillations, triggered by low powered electrical loads are a demonstration of the impact of electro-mechanical interaction and the importance of understanding the behaviour of the whole electro-mechanical system. While an aircraft drivetrain generator system is used as an example in this paper, the findings and methods are applicable to all electromechanical systems.

Future research will apply the test platform and validated models to develop strategies to prevent or damp the torsional vibrations, making possible the design of stable and reliable multi-domain systems. Modification of the generator controller 
appears to offer the greatest benefit, adding no additional components, and may be retrofitted to existing systems.

\section{ACKNOWLEDGMENT}

The authors would like to thank P. Shaw for his contribution to the development of the electro-mechanical test platform.

\section{REFERENCES}

[1] R. K. Varma, and A. Moharana, "SSR in Double-Cage Induction Generator-Based Wind Farm Connected to Series-Compensated Transmission Line," IEEE Transactions on Industrial Electronics, vol. 28, no. 3, pp. 2573-2583, 2013.

[2] J. M. Rodriguez, R. Meneses, and J. Orus, "Active vibration control for electric vehicle compliant drivetrains," in IEEE Industrial Electronics Society Annual Conference (IECON), 2013, pp. 2590-2595.

[3] S. A. Papathanassiou, and M. P. Papadopoulos, "Mechanical stresses in fixed-speed wind turbines due to network disturbances," IEEE Transactions on Energy Conversion, vol. 16, no. 4, pp. 361-367, 2001.

[4] G. Gotting, and R. W. De Doncker, "Active drive control of electric vehicles using a modal state observer," in IEEE Power Electronics Specialists Conference (PESC), 2004, pp. 4585-4590 Vol.6.

[5] F. Mei, and B. Pal, "Modal Analysis of Grid-Connected Doubly Fed Induction Generators," IEEE Transactions on Energy Conversion, vol. 22, no. 3, pp. 728-736, 2007

[6] C. Wenping, B. C. Mecrow, G. J. Atkinson, J. W. Bennett, and D. J. Atkinson, "Overview of Electric Motor Technologies Used for More Electric Aircraft (MEA)," IEEE Transactions on Industrial Electronics, vol. 59, no. 9, pp. 3523-3531, 2012.

[7] P. Kundur, N. J. Balu, and M. G. Lauby, Power System Stability and Control, New York: McGraw-Hill, 1994.

[8] D. N. Walker, C. E. J. Bowler, R. L. Jackson, and D. A. Hodges, "Results of subsynchronous resonance test at Mohave," IEEE Transactions on Power Apparatus and Systems, vol. 94, no. 5, pp. 1878 $1889,1975$.

[9] D. N. Walker, S. L. Adams, and R. J. Placek, "Torsional Vibration and Fatigue of Turbine-Generator shafts," IEEE Transactions on Power Apparatus and Systems, vol. PAS-100, no. 11, pp. 4373-4380, 1981.

[10] M. Molinas, J. A. Suul, and T. Undeland, "Extending the Life of Gear Box in Wind Generators by Smoothing Transient Torque With STATCOM," IEEE Transactions on Industrial Electronics, vol. 57, no. 2, pp. 476-484, 2010.

[11] S. Tingna, W. Jian, F. Debao, S. Zhanfeng, and X. Changliang, "Integrated control on wind turbine drive-train torque," in IEEE International Conference on Electrical Machines and Systems (ICEMS), 2011, pp. 1-5.

[12] G. Mandic, E. Ghotbi, A. Nasiri, F. Oyague, and E. Muljadi, "Mechanical stress reduction in variable speed wind turbine drivetrains," in IEEE Energy Conversion Congress and Exposition (ECCE), 2011, pp. 306-312.

[13] C. B. Mayer, "Torsional Vibration Problems and Analyses of Cement Industry Drives," IEEE Transactions on Industry Applications, vol. IA17, no. 1, pp. 81-89, 1981.

[14] Y. Ito, S. Tomura, and S. Sasaki, "Development of Vibration Reduction Motor Control for Hybrid Vehicles," in IEEE Industrial Electronics Society Conference (IECON), 2007, pp. 516-521.
[15] I. M. Elders, P. J. Norman, J. D. Schuddebeurs, C. D. Booth, G. M. Burt, J. R. McDonald, J. Apsley, M. Barnes, A. Smith, S. Williamson, S. Loddick, and I. Myers, "Modelling and Analysis of Electro-Mechanical Interactions between Prime-Mover and Load in a Marine IFEP System," in Electric Ship Technologies Symposium (ESTS), 2007, pp. 77-84

[16] M. A. Valenzuela, J. M. Bentley, and R. D. Lorenz, "Evaluation of torsional oscillations in paper machine sections," IEEE Transactions on Industry Applications, vol. 41, no. 2, pp. 493-501, 2005.

[17] R. Muszynski, and J. Deskur, "Damping of Torsional Vibrations in High-Dynamic Industrial Drives," IEEE Transactions on Industrial Electronics, vol. 57, no. 2, pp. 544-552, 2010.

[18] J. H. Holdrege, W. Subler, and W. E. Frasier, "AC Induction Motor Torsional Vibration Consideration - A Case Study," IEEE Transactions on Industry Applications, vol. IA-19, no. 1, pp. 68-73, 1983.

[19] T. Feehally, and J. M. Apsley, "The Doubly Fed Induction Machine as an Aero Generator," IEEE Transactions on Industry Applications, vol. 51, no. 4, pp. 3462-3471, 2015.

[20] W. Shi, C.-W. Kim, C.-W. Chung, and H.-C. Park, "Dynamic modeling and analysis of a wind turbine drivetrain using the torsional dynamic model," International Journal of Precision Engineering and Manufacturing, vol. 14, no. 1, pp. 153-159, 2012.

[21] J. F. Gallego Calderon, K. Branner, A. Natarajan, N. A. Cutululis, and J. C. Hansen, "Electromechanical Drivetrain Simulation," in PhD Seminar on Wind Energy in Europe, Gotland, Sweden, 2013.

[22] L. Ran, X. Dawei, and J. L. Kirtley, "Analysis of Electromechanical Interactions in a Flywheel System With a Doubly Fed Induction Machine," IEEE Transactions on Industry Applications, vol. 47, no. 3, pp. 1498-1506, 2011.

[23] I. Moir, and A. G. Seabridge, Aircraft systems : mechanical, electrical, and avionics subsystems integration, 3rd ed., Chichester: John Wiley \& Sons, 2007

[24] C. R. Avery, S. G. Burrow, and P. H. Mellor, "Electrical generation and distribution for the more electric aircraft," in 42nd International Universities Power Engineering Conference, Brighton, UK, 2007, pp. 1007-1012.

[25] "Rolls-Royce plc Trent 1000 infographic", 2014, http://www.rollsroyce.com/products-and-services/civil-aerospace/products/civil-largeengines/trent-1000/trent-1000-infographic.aspx [accessed: 15th April 2016]

[26] A. M. El-Refaie, M. R. Shah, and H. Kum-Kang, "High-Power-Density Fault-Tolerant PM Generator for Safety-Critical Applications," IEEE Transactions on Industry Applications, vol. 50, no. 3, pp. 1717-1728, 2014.

[27] R. Bojoi, A. Cavagnino, A. Tenconi, and S. Vaschetto, "Multiphase PM machine for More Electric Aircraft applications: Prototype for design validation," in IEEE Industrial Electronics Society Conference (IECON), 2012, pp. 3628-3634.

[28] W. T. Thomson, Theory of vibration with applications, 4th ed., London Chapman \& Hall, 1993.

[29] F. S. Tse, I. E. Morse, and R. T. Hinkle, Mechanical vibrations : theory and applications, Boston: Allyn and Bacon, 1978

[30] "Aircraft electric power characteristics (MIL-STD-704F)," Department of Defense, United States of America, 2004.

[31] M. B. poudeh, "An Adaptive Controller Based on Genetic Algorithm to Mitigate the Oscillations in Power System," in International Conference on Smart Manufacturing Application (ICSMA), 2008, pp. 502-507. 